\title{
ERYTHROPOIETIN SERUM LEVELS, ANAEMIA, BLOODTRANSFUSIONS AND RETINOPATHY OF PREMATURITY IN PRETERM INFANTS
}

\author{
Pia Lundgren¹, Gunnel Hellgren ${ }^{1,2}$, Aldina Pivodic ${ }^{3}$, Karin Sävman ${ }^{4}$, Lois E.H Smith ${ }^{5}$, Ann Hellström
}

\author{
${ }^{1}$ Section for Ophthalmology, Department of Clinical Neuroscience, Institute of Neuroscience and Physiology, Sahlgrenska Academy, University of \\ Gothenburg, Gothenburg, Sweden \\ 2Institute of Biomedicine, Sahlgrenska Academy, University of Gothenburg, Gothenburg, Sweden \\ ${ }^{3}$ Statistiska konsultgruppen, Gothenburg, Sweden \\ ${ }^{4}$ Department of Paediatrics, Institute of Clinical Sciences, Sahlgrenska Academy, University of Gothenburg, Gothenburg, Sweden \\ 5The Department of Ophthalmology, Boston Children's Hospital, Harvard Medical School, Boston, MA
}

\section{Aim}

This study evaluated the longitudinal relationship between serum Erythropoietin (EPO) levels and anaemia, blood transfusions, and retinopathy of prematurity (ROP) requiring treatment in very preterm infants.

\section{Background}

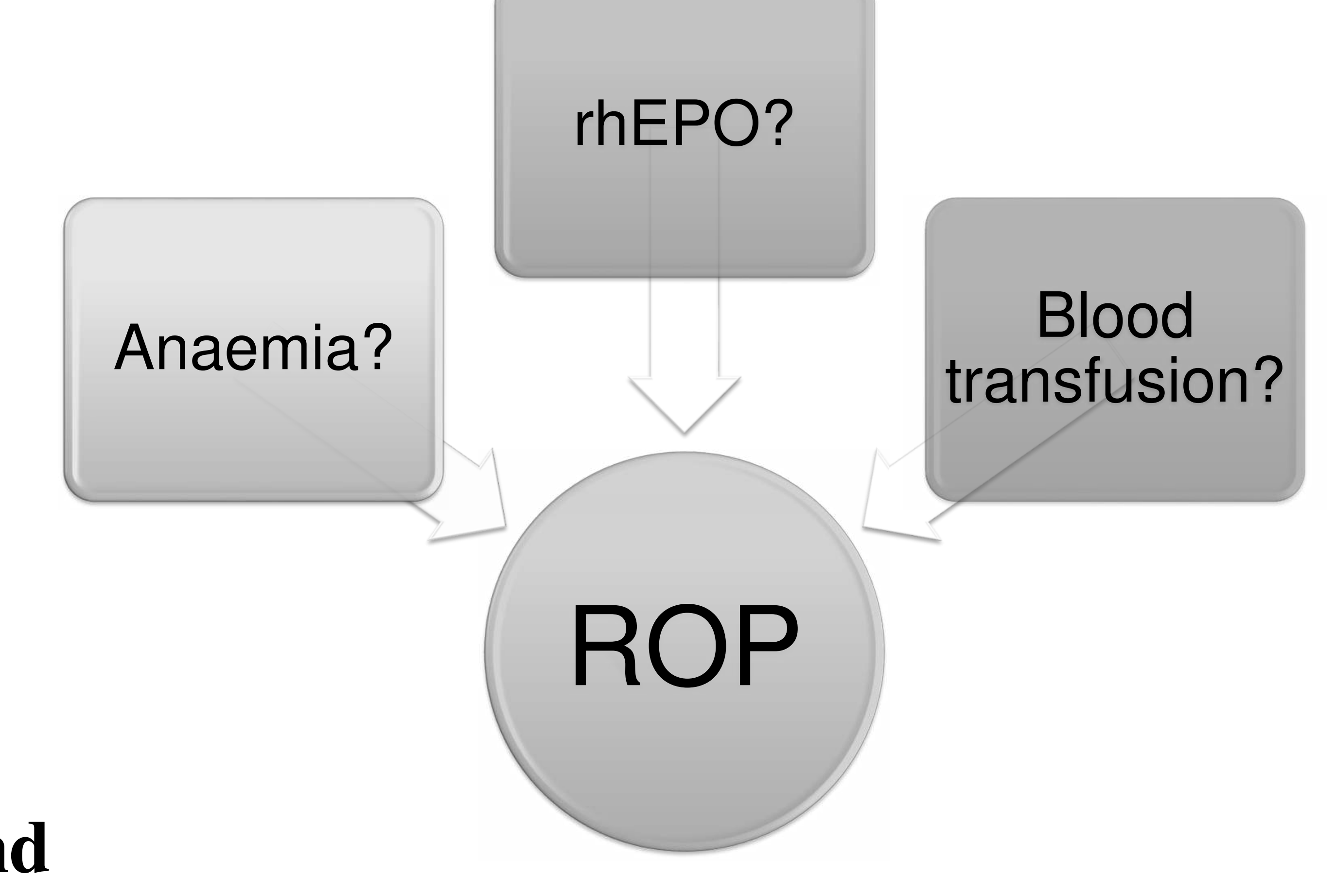

Preterm infants with anaemia are treated with recombinant human erythropoietin (rhEPO). It is debated whether rhEPO treatment is a risk factor for ROP or not.

\section{Study subjects and methods}

We studied 78 infants with gestational age $(\mathrm{GA})<28$ weeks with a mean (SD) GA at birth of 25.4 (1.4) weeks and mean (SD) birth weight of 797 (223) grams, 28\% (22/78) required ROP treatment.

- EPO: serum were analyzed at postnatal days 1, 7, 14, 28 and at postmenstrual age 32, 36 and 40 weeks.

- Haemoglobin: analyses of routine blood samples according to local guidelines and on clinical indications.

- Anaemia was defined as haemoglobin $\leq 110 \mathrm{~g} / \mathrm{L}$.

- The dates and volumes of blood transfusions were recorded.

Result 1: EPO levels at postnatal day 7 was higher

Mean EPO levels was higher at postnatal day $7(14.2 \mathrm{mIU} / \mathrm{mL}$ vs 10.8 $\mathrm{mIU} / \mathrm{mL}, \mathrm{p}=0.003$ ) in infants requiring treatment compared to in infants not requiring treatment for severe ROP.

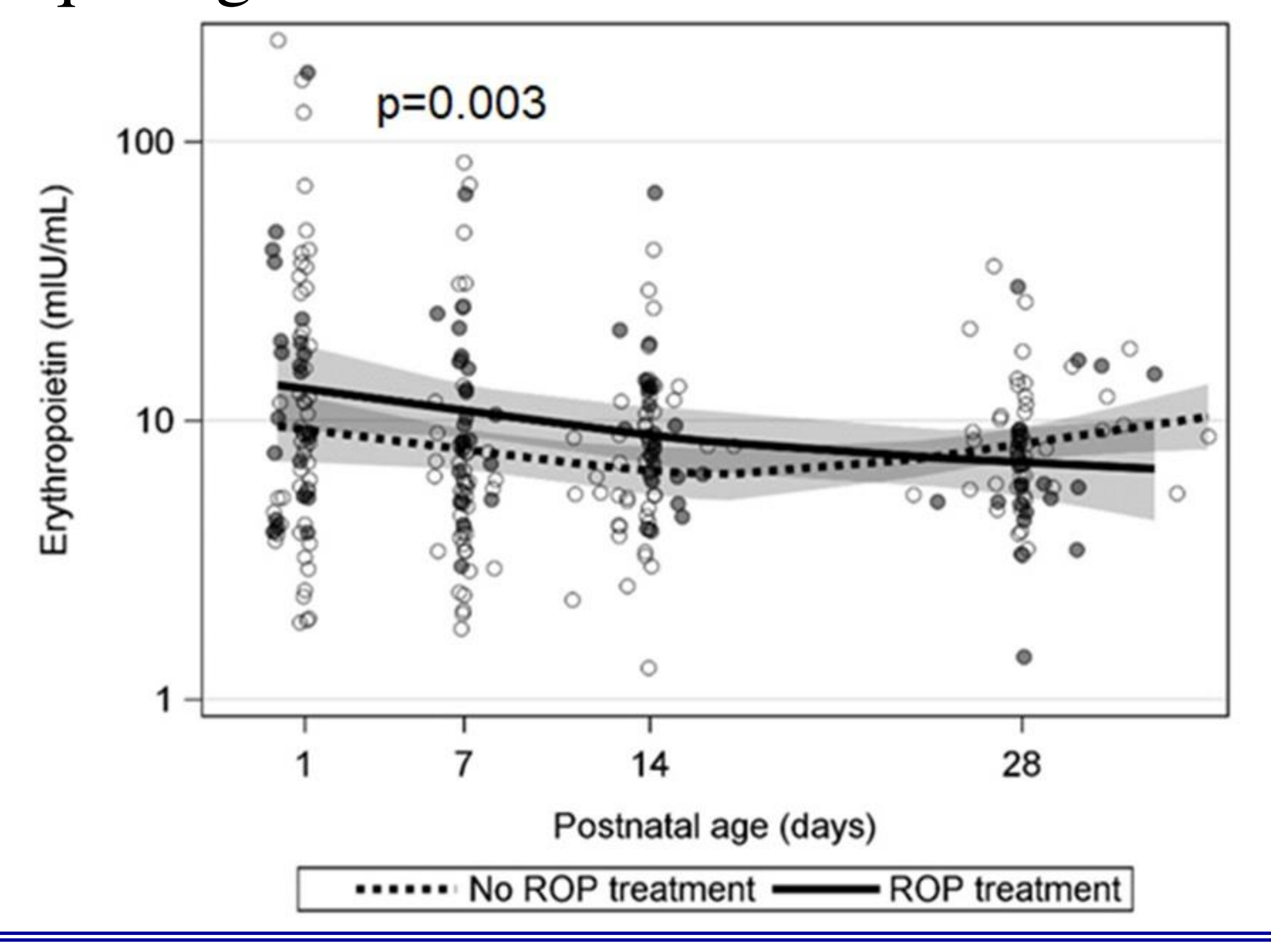

Conclusions

Elevated serum EPO level was not a risk factor for ROP that required treatment, after adjusting for $\mathrm{GA}$ at birth anaemia.

Anaemia during first postnatal week was found to be an independent risk factor for ROP requiring treatment.

Result 2: Anaemia was more frequent in infants treated for ROP During postnatal week 1 , infants requiring ROP treatment more frequently developed anaemia ( $42.9 \%$ vs $8.0 \%, \mathrm{p}=0.003)$.

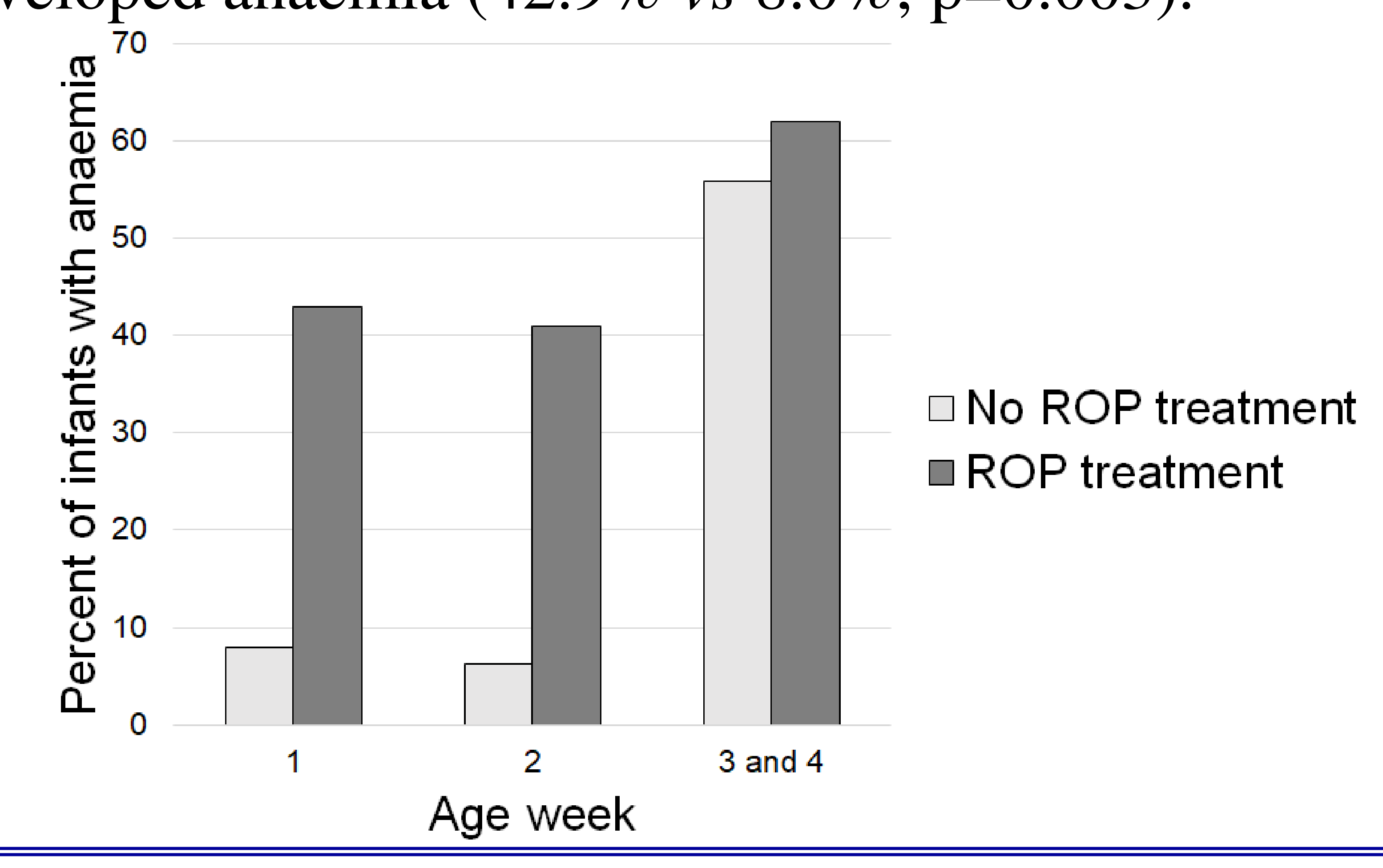

Result 3: EPO levels associated with anaemia but not ROP When comparing infants without or with anaemia; EPO levels at postnatal day 7 were not significantly different between infants that required ROP treatment or not; no anaemia (mean 8.5 vs 10.4 $\mathrm{mIU} / \mathrm{mL}, \mathrm{p}=0.14$ ) and with anaemia (mean $21.6 \mathrm{vs} 18.1 \mathrm{mIU} / \mathrm{mL}$, $\mathrm{p}=0.82)$.

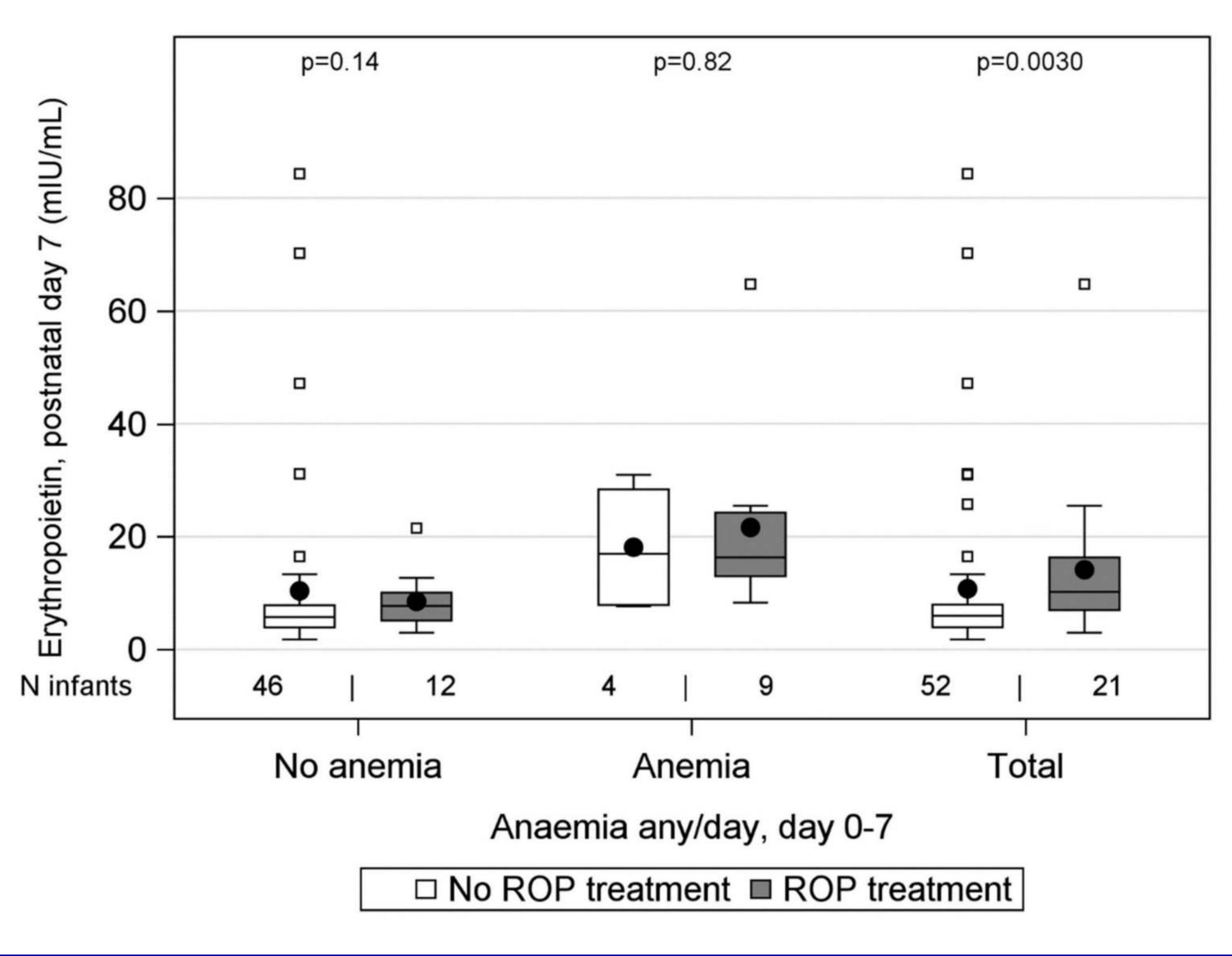

- Blood transfusion was not found to be a significant risk factor for ROP requiring treatment when adjusting for GA at birth.

- In multivariable analyses adjusted for GA at birth, anaemia during postnatal week 1 (OR 6.94, 95\% CI 1.05 - 45.75, p=0.044) remained as risk factors for ROP requiring treatment, but elevated EPO level postnatal day 7 was no longer significant.

This study was supported by grants provided by the Swedish Research Council (DNR\# 2011-2432), Gothenburg County Council (ALFGBG-426531), De Blindas Vänner, Kronprinsessan Margaretas Arbetsnämnd för synskadade, Stiftelsen Handlanden Herman Svenssons fond för blinda och synsvaga Carmen och Bertil Regnérs Stiftelse, Cronqvists stiftelse, NIH EY024864, EY017017, P01 HD18655, Lowy Medical Research Institute. 